cost, ZWO will be allowed to allocate 20 per cent of the observing time to Dutch astronomers. It has not yet been decided precisely how the Netherlands will help to solve the manpower shortage. When the observatory is fully operational, Professor Smith estimates that about 30 technical staff will be needed in La Palma at any one time. The difficulty is in persuading sufficient British scientists to uproot themselves for three years at a time.

ZWO has decided to pay its share out of its existing budget of about $£ 40$ million a year. Most of the money will come from the $£ 6$ million a year now spent on astronomy, implying a major shift in astronomy funding. Although most Dutch astronomers are expected to welcome the agreement, radioastronomers may feel hard done by.

The next step is for Professor van Lieshout, director of ZWO, to obtain the approval of the Dutch minister for science, who is reported to be enthusiastic. But the imminent Dutch election could mean that the issue will have to be decided by a new minister. All being well, however, Professor van Lieshout hopes that an agreement could be signed and sealed within the next four months.

Judy Redfearn

\section{Toxic waste}

\section{Dutch dumps}

\section{Amsterdam}

The cost to the Netherlands of dealing with chemical waste from years of heavy industrialization is mounting. So far about 3,000 dumps containing chemical waste have been found, 500 of them a recognized danger to public health. The Minister for Public Health and Environmental Protection estimated a few months ago that it would cost about $£ 200$ million to clear the 500 dangerous dumps, and this estimate is now $£ 400$ million.

In the village of Lekkerkerk, not far from the heavily concentrated chemical industries of Rotterdam, many buildings were found to have been built on a chemical waste dump. About 1,700 drums were recovered from the site, containing materials such as toluene and xylene from the dye industry and metals such as cadmium, zinc and lead. Some $\mathbf{3 0 0}$ houses were evacuated and 150,000 tons of polluted soil have had to be removed, while medical examinations may yet be carried out on the population. Several more chemical waste dumps have since been found in the same area.

After cases of cattle infertility and the discovery of dead birds, an investigation by the municipal environmental laboratory of Amsterdam has revealed that the Volgermeerpolder, a marshy area 5 miles from the centre of Amsterdam, contains about 10,000 drums of chemical waste from a 2,4,5-T factory previously owned by Philips-Duphar. The factory ceased production in 1969 and was completely dismantled and dumped in the Atlantic, but its waste remained.

According to Dr H. Heida, director of the Amsterdam environmental laboratory, the drums contain a wide range of chemicals, including chlorobenzene and chlorophenol. However, some of the drums are known to contain 2,4,5-T and possibly the dioxin $2,3,7,8$-tetrachlorocyclodibenzo- $p$-dioxin $(2,3,7,8$-TCDD), and it is this latter compound which it is feared may form the real danger.

Analysis of soil, water and livestock and of produce from gardens in the area has revealed the presence of chemicals from the dump in concentrations of tenths to hundredths of milligrammes per kilogramme weight.

However, the future of the dump rests on the problem of clearly identifying $2,3,7,8-T C D D$. Samples from the drums have been analysed by Professor $O$. Hutzinger's team at Amsterdam University

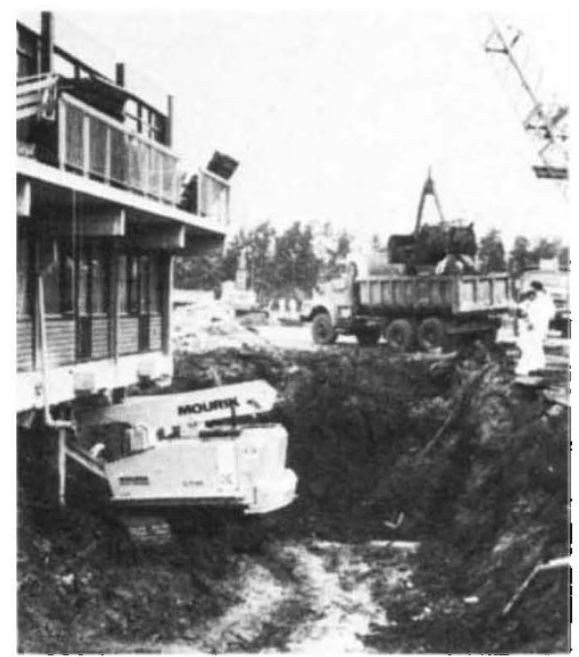

The clearing of Lekkerkerk

and have also been sent to Milan for analysis by the laboratory involved in investigating the Séveso incident. A definite solution to the problem is not expected before the summer.

These pollution scandals prompted a national inventory of chemical waste in the Netherlands due to be completed by the end of 1980 . So far, however, only two of the eleven Dutch provinces have reported their findings.

The problems of the Netherlands have also attracted international interest. Dr David Costle, administrator of the US Environmental Protection Agency, visited the Lekkerkerk dump while he was in the Netherlands to sign a memorandum on cooperation between the two countries. $\mathrm{Dr}$ Tolba of the United Nations Environmental Programme, a regular visitor to the country, is particularly interested in the chemical pollution problems.

The latest revelation was in December of last year, when small amounts of the toxic substance methyl bromide were found in drinking water in the horticultural area between The Hague and Rotterdam. This chemical is used by market gardeners to disinfect the soil, and an estimated 2,000 tons a year are used in this area -30 per cent of the total consumption in the European Community. The poison had apparently seeped through the PVC tubes used for private water distribution. As a result, the Minister for Public Health has made public water supply companies responsible also for private supply pipes. However, it now turns out that PVC tubes are widely used in the Netherlands for transporting water which has been tested for pollutants such as methyl bromide.

Casper Schuuring

\section{Genetic engineering}

\section{Planning bugs}

\section{Washington}

Echoes of the fierce public debates of four years ago are being heard once again in and around Cambridge, Massachusetts, as local city councils discuss the conditions they will place on the genetic engineering companies springing up in their midst.

The tones of the debate are more muted than before. And in each of the four communities - Cambridge, Waltham, Somerville and Newton - the talk this time is of negotiation rather than confrontation. Nevertheless, there is sufficient concern among the companies for the head of at least one to suggest the need for a "more coherent policy" towards local regulation, possible at the state level.

The most significantly affected so far seems to have been Genetics Institute. This is the company which has been set up by $\mathrm{Dr}$ Mark Ptashne, professor of molecular biology at Harvard University, and a local management consultant, Mr Tom Hexner, on privately-raised venture capital, after the Harvard faculty voted against university participation (see Nature 27 November 1980). Its backers include Venrock, a venture capital firm owned by the Rockefeller family, and Mr William Paley of Columbia Broadcasting.

Now the company faces a new hurdle gaining acceptance in the local community. Last November, it applied to build a laboratory in Somerville, just inside the city's border with Cambridge and a few blocks from the university biology laboratories. The application has kindled a fierce public debate. At one point, for example, local citizens had suggested that research should be limited to P1 and P2 physical containment facilities, even stricter than restrictions in Cambridge, which allow work up to the P3 level.

City council members who were originally in favour of granting permission for the new laboratories with few strings attached have backed off in the face of the public controversy; many are preoccupied with severe budget cuts that have resulted from a recent reduction in property taxes.

At a public meeting last Thursday, the 